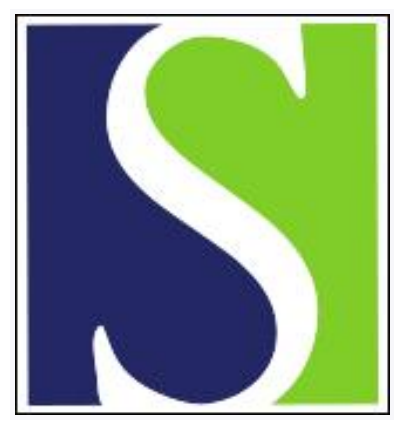

Scand J Work Environ Health 2015;41(4):413-416

https://doi.org/10.5271/sjweh.3501

Published online: 06 May 2015, Issue date: 01 Jul 2015

Shift work and mental health sickness absence: a 10-year observational cohort study among male production workers

by Norder G, Roelen CAM, Bültmann U, van der Klink JJL

Epidemiological data on mental sickness absence among shift workers is lacking. This 10-year observational study showed that mental sickness absence is as common among shift workers as it is among daytime workers. There is no need for health providers to advise against returning to shift work after recovery from mental sickness absence.

Affiliation: ArboNed, PO Box 85091, 3508 AB Utrecht, The Netherlands. giny.norder@arboned.nl

Refers to the following texts of the Journal: $2011 ; 37(5): 402-410$ 2010;36(2):81-84 2010;36(2):121-133 2009;35(5):361-367 2006;32(6):502-514 2004;30(2):139-148

The following article refers to this text: 2016;42(4):346-353

Key terms: absenteeism; cohort study; ICD-10; incidence; irregular work hour; men; mental disorder; mental health; production worker; psychiatric disorder; shift work; sick leave; sickness absence; worker

This article in PubMed: www.ncbi.nlm.nih.gov/pubmed/25945780

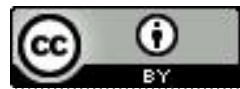




\title{
Shift work and mental health sickness absence: a 10-year observational cohort study among male production workers
}

\author{
by Giny Norder, MD,1, 2 Corné AM Roelen, MD, PhD,1, 2 Ute Bültmann, PhD, ${ }^{2}$ Jac JL van der Klink, MD, \\ $P h D^{2,3}$
}

\begin{abstract}
Norder G, Roelen CAM, Bültmann U, van der Klink JJL. Shift work and mental health sickness absence: a 10-year observational cohort study among male production workers. Scand J Work Environ Health. 2015;41(4):412-416. doi:10.5271/sjweh.3501
\end{abstract}

\begin{abstract}
Objectives Epidemiological studies investigating mental-health-related sickness absence (SA) among shift workers are lacking. This 10-year observational study investigated the risk of mental health SA among shift compared with day workers.

Methods The data of 5826 male production workers were used for analyses: 4288 (74\%) shift and 1538 (26\%) day workers. The risk of mental health SA was analyzed with Cox regression analysis. Hazard ratios (HR) and $95 \%$ confidence intervals $(95 \% \mathrm{CI})$ were adjusted for age and occupational grade.

Results During a 10-year follow-up, 351 shift workers and 126 day workers had incident mental health SA. The risk of mental health SA did not differ (HR 1.03, 95\% CI 0.84-1.26) between shift and day workers. Among shift workers, the risk of SA due to mood disorders (HR 1.87, 95\% CI 0.73-4.76) was non-significantly higher than among day workers. A total of 96 shift workers and 21 day workers had recurrent mental health SA. The risk of recurrent mental health SA did not differ (HR 1.04, 95\% CI 0.62-1.74) between shift and day workers.
\end{abstract}

Conclusion The risk of incident and recurrent mental health SA did not differ between shift and day workers.

Key terms absenteeism; ICD-10; incidence; irregular work hour; men; mental disorder; psychiatric disorder; sick leave.

In today's Western societies, only a quarter of the labor force works regular 9-5 office hours, while the remainder is engaged in shift work or has irregular work hours (1). More often than day workers, shift workers report mental health symptoms, such as fatigue, nervousness, anxiety, and depressed mood; they also use sleeping pills and tranquillizers more often $(2,3)$. Shift workers may experience sleep problems when the circadian rhythm promotes alertness. Short or poor sleep leads to insufficient recovery and stress $(4,5)$. However, disturbed sleep is not the only pathway between shift work and mental health. Some neuroendocrine mechanisms may contribute to depressed mood among shift workers. Shift work reduces glucocorticoid sensitivity of the peripheral tissues, resulting in functional hypercortisolism (6). Glucocorticoid resistance and hyperactivity of the hypothalamic-pituitary-adrenocortical axis play a role in the pathogenesis of depression and other psychiatric disorders (7). Shift work also disturbs nocturnal melatonin secretion, and reduced endogenous melatonin levels have been associated with the onset of depression and anxiety disorders (8).

Besides disturbed sleep and neuroendocrine mechanisms, psychosocial pathways could explain why shift workers experience more mental health symptoms than day workers $(3,9)$. Shift work interferes with participation in family life and alienates workers from their social environment by desynchronization from daily societal habits. Haines et al (10) estimated that $70 \%$ of the effect of shift work on depression is direct and $30 \%$ is mediated through work-family conflict and social desynchronization.

1 ArboNed Occupational Health Service, Utrecht, The Netherlands.

2 Department of Health Sciences, Division of Community and Occupational Medicine, University Medical Center Groningen, University of Groningen, Groningen, The Netherlands.

3 School of Social and Behavioral Sciences, Tilburg University, Tilburg, The Netherlands.

Correspondence to: Giny Norder, ArboNed, PO Box 85091, 3508 AB Utrecht, The Netherlands. [E-mail: giny.norder@arboned.nl] 
The fact that shift workers experience mental health problems more often than day workers does not necessarily imply they are off work due to mental disorders more frequently. Merkus et al (11) found inconclusive evidence for increased sickness absence (SA) levels among shift workers. A variety of health-related and decisional theories try to explain why workers report sick in a particular case. The threshold of taking sick leave may differ between shift and day workers. For example, shift workers may refrain from reporting sick when they think it will be difficult to find substitutes. We found no epidemiological studies that investigated SA due to mental disorders among shift workers. The objective of this observational study was to compare shift and day workers for risk of mental health SA, addressing the research questions: (i) Do shift workers have a higher risk of mental health SA than day workers? (ii) Do shift workers have a higher risk of recurrent mental health SA than day workers?

\section{Methods}

\section{Study population}

The study population consisted of 6678 male production workers employed at a steel mill. SA data were retrieved from an occupational health service (OHS) register and work schedules were obtained from the employer's payroll. Baseline was set at 1 January 2002 and workers were followed until 31 December 2011. We excluded workers whose shift schedules were not available $(\mathrm{N}=527)$ or differed from a 5 -shift schedule $(\mathrm{N}=107) ; 218$ workers were excluded because they had had mental health SA in the two years prior to baseline. Consequently, the data of 5826 male production workers were analyzed: 4288 (74\%) shift workers with a forward rotating 5-shift schedule MMEEXNNXXX ( $\mathrm{M}=$ morning 06:00-14:00 hours, $E=$ evening 14:00-22:00 hours, $\mathrm{N}=$ night 22:00-06:00 hours, and $\mathrm{X}=$ day off) and 1538 (26\%) day workers (08:00-17:00 hours). During followup, 1484 (1084 shift and 400 day) workers left employment; the mean (standard deviation) follow-up period was 7.7 (3.0) years. The Medical Ethics Committee of the University Medical Center Groningen granted ethical clearance for this register-based study.

\section{Mental health SA}

SA was defined as a financially compensated temporary leave from work due to work-related and non-workrelated injuries and illness. In the Netherlands, SA is employer-compensated when medically certified by an occupational physician (OP) within 42 days of reporting sick. SA certified within the International Classification of Diseases (ICD-10) categories of emotional disturbance (ICD-10 R45) or mental and behavioral disorder (ICD-10 F00-F99) was defined as mental health SA. Recurrent mental health SA was defined as any mental health SA episode occurring $>28$ days after recovery from the first mental health SA episode since January 2002.

\section{Statistics}

All analyses were performed with SPSS Statistics version 20 (IBM, Armonk, NY, USA). The risks of incident and first recurrence of mental health SA were analyzed with Cox regression including work schedule (shift versus daytime) as independent variable with age (continuous variable) and occupational grade (discrete variable, $1=$ unskilled, $2=$ semi-skilled, $3=$ skilled steel workers, $4=$ maintenance technicians, and $5=$ supervisors) as covariates.

During the study period, 386 workers changed their work schedule: 292 from shift to day work and 94 from day to shift work. Ten percent of the workers who changed their work schedule had mental health SA as compared with $8 \%$ of those who did not change their work schedule. Information on why workers changed their work schedule was not available. To exclude potential interactive effects between mental health SA and work schedule, we performed a sensitivity analysis including the $5440(3996$ shift and 1444 day) workers who did not change their work schedule during the study period.

\section{Results}

Day workers were older and worked more hours/week in higher grade jobs than shift workers (table 1).

In total, 477 (351 shift and 126 day) workers had mental health SA. Shift workers had no increased risk of incident mental health SA [hazard ratio (HR) 1.03, 95\% confidence interval (95\% CI) $0.84-1.26$ ] compared with day workers. Shift workers had higher risks of SA due to mood and neurotic disorders, although the difference between shift and day workers was not significant (table 2).

Of the 477 workers who had had mental health SA, 117 (96 shift and 21 day) workers had recurrent mental health SA. Shift workers had no increased risk of recurrent mental health SA (HR 1.04, 95\% CI 0.62-1.74) compared with day workers.

\section{Sensitivity analysis}

Of the workers with no change in work schedule, 357 (251 shift and 106 day) workers had incident and 107 (86 
Table 1. Baseline characteristics of the study population of male production workers ( $\mathrm{N}=5826)$. [SD=standard deviation]

\begin{tabular}{|c|c|c|c|c|c|c|c|c|c|}
\hline & \multicolumn{4}{|c|}{ Shift workers (N=4288) } & \multicolumn{4}{|c|}{ Day workers ( $\mathrm{N}=1538$ ) } & \multirow{2}{*}{$\frac{\text { Analysis }}{\mathrm{P}}$} \\
\hline & Mean & SD & $\mathrm{N}$ & $\%$ & Mean & SD & $\mathrm{N}$ & $\%$ & \\
\hline Age & 45.3 & 8.0 & & & 47.2 & 7.0 & & & $<0.01^{a}$ \\
\hline \multicolumn{10}{|l|}{ Marital status } \\
\hline Single & & & 875 & 20 & & & 325 & 21 & \\
\hline Married & & & 3092 & 71 & & & 1135 & 74 & \\
\hline Divorced/widow & & & 321 & 9 & & & 78 & 5 & $0.11^{\mathrm{a}}$ \\
\hline Work hours per week & 33.8 & 1.9 & & & 39.6 & 2.0 & & & $<0.01^{b}$ \\
\hline Employment duration & 18.6 & 7.6 & & & 22.3 & 8.3 & & & $<0.01^{b}$ \\
\hline \multicolumn{10}{|l|}{ Occupational grade } \\
\hline Unskilled & & & 386 & 10 & & & 68 & 4 & \\
\hline Semi-skilled & & & 1685 & 39 & & & 334 & 22 & \\
\hline Skilled & & & 1578 & 37 & & & 657 & 43 & \\
\hline Technician/supervisor & & & 639 & 14 & & & 479 & 31 & $<0.01^{a}$ \\
\hline
\end{tabular}

Table 2. Risk of mental health sickness absence (SA). The table shows mental SA stratified by ICD-10 diagnosis and hazard ratios $(\mathrm{HR})$ with related $95 \%$ confidence intervals $(95 \% \mathrm{Cl})$ of $\mathrm{Cox}$ regression analysis, adjusted for age and occupational grade; $\mathrm{HR}>1$ reflects higher and $\mathrm{HR}<1$ lower risk of mental health $\mathrm{SA}$ among shift compared with day workers.

\begin{tabular}{|c|c|c|c|c|c|c|c|}
\hline & \multirow[t]{2}{*}{ ICD-10 } & \multicolumn{2}{|c|}{$\begin{array}{c}\text { Shift } \\
\text { worker } \\
(\mathrm{N}=4288)\end{array}$} & \multicolumn{2}{|c|}{$\begin{array}{c}\text { Day } \\
\text { worker } \\
(\mathrm{N}=1538)\end{array}$} & \multicolumn{2}{|c|}{ Cox regression } \\
\hline & & $\mathrm{N}$ & $\%^{a}$ & $\mathrm{~N}$ & $\%^{a}$ & $\mathrm{HR}$ & $95 \% \mathrm{Cl}$ \\
\hline $\begin{array}{l}\text { Emotional } \\
\text { disturbance }\end{array}$ & R45 & 154 & 4 & 53 & 3 & 0.72 & $0.49-1.05$ \\
\hline Mood disorders & F30-39 & 27 & 1 & 8 & 1 & 1.87 & \\
\hline $\begin{array}{l}\text { Neurotic } \\
\text { disorders }\end{array}$ & F $40-49$ & 155 & 4 & 57 & 4 & 1.29 & $0.89-1.87$ \\
\hline $\begin{array}{l}\text { Other mental } \\
\text { disorders }\end{array}$ & F00-29; F50-99 & 15 & 0 & 8 & 1 & $N A^{b}$ & NA \\
\hline All & R45; F00-99 & 351 & 8 & 126 & 8 & 1.03 & $0.84-1.26$ \\
\hline
\end{tabular}

a Percentage of the total number of shift or day workers.

${ }^{b}$ Not analyzed because of the low number of events.

shift and 21 day) workers had recurrent mental health SA. The risks of incident (HR 1.19, 95\% CI 0.88-1.60) and recurrent (HR 0.83, 95\% CI 0.48-1.43) mental health SA did not differ between shift and day workers.

\section{Discussion}

Our 10-year observational study showed that shift workers did not have a higher risk of incident and recurrent mental health SA than day workers. The risk of incident SA due to mood disorders was higher among shift than day workers but did not differ significantly. The statistical power of a Cox regression model including 3 independent variables and 27 events (ie, SA episodes due to mood disorders) is debatable, although Vittinghoff and McCulloch (12) showed that CI coverage, type I error, and relative bias with 5-9 events per variable were comparable to those with 10-16 events per variable. In a previous Dutch study, Driessen et al (13) found a higher risk of depressed mood among male and actual shift workers as compared with female and former shift workers, but the results were no longer significant when educational level and psychosocial work factors were controlled for.

\section{Selection issues}

Shift workers may represent a relatively healthy part of the working population. This healthy worker selection starts with the worker's judgement of his ability to withstand shift work and may be reinforced by preplacement medical assessments (14). Healthy worker selection then continues in terms of a survival effect in which less healthy shift workers are likely to transfer to daytime work or quit the job. We had no information about pre-employment selection mechanisms and could not identify which day workers were former shift workers because payroll data from before January 2000 were not available. The sensitivity analysis including only the workers with the same schedule throughout the 10-year study period confirmed the finding that the risk of mental health SA did not differ between shift and day workers.

\section{Methodological considerations}

Although the use of OP-recorded ICD-10 diagnoses restricted recall and social desirability bias, the reliability of OP-diagnoses is being debated. O'Niell et al (15) found no systematic difference between OP and psychiatrists in their diagnostic labelling of mental ill-health, although within-group reliabilities were low for some diagnoses, particularly 'stress'. We limited potential diagnostic misclassification by using main ICD-10 (eg, 
'neurotic disorders') instead of specific (eg, burnout, adjustment disorder, or anxiety disorder) diagnoses.

All workers were employed at the same company. Consequently, differences in mental health SA could not be attributed to organizational policies and practices. The study population is a convenience sample, which may not be representative of the general working population. Furthermore, only men working in a forwardrotating 5-shift schedule were included. The results might not generalize to female shift workers (eg, in healthcare) and workers engaged in other shift systems.

\section{Concluding remarks}

We conclude that the risk of incident and recurrent mental health SA did not differ between shift and day workers. Larger-scale studies are required to differentiate between the mental health effects of shift work and mental health SA diagnoses. Furthermore the relationship between shift work and SA due to mood disorders should be examined in more detail.

\section{References}

1. Härmä M, Kecklund G. Shift work and health - how to proceed? Scand J Work Environ Health. 2010;36:81-4. http:// dx.doi.org/10.5271/sjweh.2902.

2. Bara AC, Arber S. Working shifts and mental health - findings from the British Household Panel Survey (1995-2005). Scand J Work Environ Health. 2009;35:361-7. http://dx.doi. org/10.5271/sjweh.1344.

3. Vogel M, Braungardt T, Meyer W, Schneider W. The effect of shift work on physical and mental health. J Neural Transm. 2012;119:1121-32. http://dx.doi.org/10.1007/s00702-0120800-4.

4. Sallinen M, Kecklund G. Shift work, sleep, and sleepiness differences between shift schedules and systems. Scand J Work Environ Health. 2010;36:121-33. http://dx.doi.org/10.5271/ sjweh.2900.

5. Härmä M. Workhours in relation to work stress, recovery and health. Scand J Work Environ Health. 2006;32:502-15. http:// dx.doi.org/10.5271/sjweh.1055.
6. Kino T, Chrousos GP. Acetylation-mediated epigenetic regulation of glucocorticoid receptor activity: circadian rhythm-associated alterations of glucocorticoid actions in target tissues. Mol Cell Endocrinol. 2011;336:23-30. http:// dx.doi.org/10.1016/j.mce.2010.12.001.

7. Pariante CM. Risk factors for development of depression and psychosis. Glucocorticoid receptors and pituitary implications for treatment with antidepressant and glucocorticoids. Ann N Y Acad Sci. 2009;1179:144-52. http://dx.doi.org/10.1111/ j.1749-6632.2009.04978.x.

8. Rahman SA, Marcu S, Kayumov L, Shapiro CM. Altered sleep architecture and higher incidence of subsyndromal depression in low endogenous melatonin secretors. Eur Arch Psychiatry Clin Neurosci. 2010;260:327-35. http://dx.doi.org/10.1007/ s00406-009-0080-7.

9. Jansen NW, Kant I, Nijhuis FJ, Swaen GM, Kristensen TS. Impact of work time arrangements on work - home interference among Dutch employees. Scand J Work Environ Health. 2004;30:139-48. http://dx.doi.org/10.5271/ sjweh.771.

10. Haines VY, Marchand A, Rousseau V, Demers A. The mediating role of work-to-family conflict in the relationship between shift work and depression. Work and Stress. 2008;22:341-56. http://dx.doi.org/10.1080/02678370802564272.

11. Merkus SL, van Drongelen A, Holte KA, Labriola M, Lund T, van Mechelen W, van der Beek AJ. The association between shift work and sick leave: a systematic review. Occup Environ Med. 2012;69:701-12. http://dx.doi.org/10.1136/ oemed-2011-100488.

12. Vittinghoff E, McCulloch CE. Relaxing the rule of ten events per variable in logistic and Cox regression. Am J Epidemiol. 2007;165:710-8. http://dx.doi.org/10.1093/aje/kwk052.

13. Driesen K, Jansen NW, van Amelsvoort LG, Kant I. The mutual relationship between shift work and depressive complaints - a prospective cohort study. Scand J Work Environ Health. 2011;37:402-10. http://dx.doi.org/10.5271/ sjweh.3158.

14. Knutsson A. Methodological aspects of shift-work research. Chronobiol Int. 2004;21:1037-47. http://dx.doi.org/10.1081/ CBI-200038525.

15. O’Niell E, McNamee R, Agius R, Gittins M, Hussey L, Turner $\mathrm{S}$. The validity and reliability of diagnoses of work-related mental ill-health. Occup Environ Med. 2008;65:726-31. http://dx.doi.org/10.1136/oem.2008.039008.

Received for publication: 6 February 2015 